
$\$$ Research Square
Preprints are preliminary reports that have not undergone peer review.
They should not be considered conclusive, used to inform clinical practice, or referenced by the media as validated information.

\title{
Subcutaneous Onlay Laparoscopic Approach (SCOLA) for Umbilical Hernia with Diastasis of Rectus Abdominis Muscle: A Case Report
}

Halil Afsin Tasdelen ( $\sim$ tasdelen35@yahoo.com )

Trabzon Kanuni Egitim ve Arastirma Hastanesi https://orcid.org/0000-0003-0198-1827

\section{Research Article}

Keywords: Diastasis recti, SCOLA, Umbilical Hernia, Laparoscopy

Posted Date: May 7th, 2021

DOI: https://doi.org/10.21203/rs.3.rs-497788/v1

License: (c) (1) This work is licensed under a Creative Commons Attribution 4.0 International License.

Read Full License 


\section{Abstract}

Diastasis of the rectus abdominis muscles (DRAM) is a common pathology, usually associated with midline abdominal wall hernias. The midline ventral hernias with diastasis have a significantly high recurrence rate, so repairing the hernia defect and the diastasis should be considered. Claus et al. previously described the subcutaneous onlay laparoscopic approach (SCOLA). We report a case of diastasis recti associated with umbilical hernia repaired with SCOLA technique. A 46-year-old male patient presented with a disturbing bulge in the upper midline and painful umbilical swelling. The CT scan followed by physical examination revealed $28 \mathrm{~mm}$. umbilical hernia and $35 \mathrm{~mm}$. diastasis recti. We aimed to introduce the SCOLA technique using a narrated video clip and showed all the critical steps and anatomical landmarks in the video. The postoperative period was uneventful, and the patient was discharged on the second postoperative day. The SCOLA technique is a feasible and reproducible alternative for the repair of midline hernias associated with DRAM.

\section{Introduction}

Diastasis of the Rectus Abdominis Muscles (DRAM) is a common pathology. According to Beer et al., it defines as the distance between medial borders of the Rectus Abdominis Muscles is more than $2.2 \mathrm{~cm}$. wide. [1]. It is mostly seen in multiparous women and generally repairs by plastic surgeons as an aesthetic procedure. It represents bulging in the anterior abdominal wall and some symptoms such as low back pain, constipation, and aesthetic concerns. DRAM is usually associated with midline hernias. Repairing the midline hernia alone in patients with diastasis has been associated with a high risk of recurrence due to the widened and weakened linea alba. Kohler et al. demonstrated that midline ventral hernias with diastasis have a significantly higher recurrence rate than hernias without DRAM [2].

\section{Case Report}

A forty-six-year-old male patient presented with the symptomatic primary umbilical hernia and the simultaneous presence of DRAM. His main complaint was painful umbilical swelling and a disturbing bulge in the midline of the abdominal wall. Previous surgical and medical history was insignificant, and no known allergies. The CT scan followed by physical examination revealed $28 \mathrm{~mm}$. umbilical hernia and $35 \mathrm{~mm}$. diastasis recti. The results of the preoperative laboratory tests were clinically insignificant.

The patient was placed in the supine position, and the legs were separated. The surgeon was between the patient's legs, and the assistants were on either side of the patient. A two-centimeter suprapubic midline transverse incision was made. Finger dissection was performed lateral and superior direction to separate subcutaneous tissue from the anterior rectus sheath. A purse-string suture was performed in the incision, and a 10-millimeter balloon trocar was placed and secured to prevent $\mathrm{CO}_{2}$ leakage. Two additional 5-millimeter trocars were entered under direct vision. The $\mathrm{CO}_{2}$ pressure was set to 6-8 $\mathrm{mmHg}$, and the initial dissection was started with the Ligasure device. After the bilateral anterior rectus sheath was dissected from the subcutaneous tissue, the dissection was continued with a monopolar hook in the 
midline. The hernia sac was found and separated from the umbilicus. The dissection progressed on the linea alba until it reached the xiphoid; thus, both dissected areas were connected. Borders of the dissected space were checked with the needles. The opened hernia sac was closed with a two-zero polyglactin suture. Medial edges of the bilateral rectus abdominis muscles were marked with the tip of a sterilized surgical marking pen to identify the umbilical defect and diastasis borders. Repair of the umbilical hernia defect and plication of the diastasis was performed with 0 barbed suture in running fashion. Dissected and developed space was measured to decide the mesh size. A 15 by 20 -centimetre self-gripping polyester mesh was inserted through the optical port and unfolded. Two-zero polyglactin sutures were performed at the four edges of the mesh. The umbilicus was fixated with two stitches to the aponeurosis in the midline. Two redon drains were inserted through working ports, and trocar sites were closed with subcuticular stitches. The overall surgical time was 85 minutes. The postoperative period was uneventful, and the patient was discharged on the second postoperative day. The drains were kept in place for eight days after surgery and removed after the drainage decreased under $20 \mathrm{ml}$ per day.

\section{Discussion}

The concomitance of midline hernias and DRAM is commonly seen, and both should be repaired in the same session as mostly recommended. Kohler et al. demonstrated that midline ventral hernias with diastasis have a significantly higher recurrence rate than hernias without DRAM [2]. The use of absorbable sutures and non-use of meshes have been reported as the other technical factors for recurrence [2]. Several open, laparoscopic, hybrid, or endoscopic techniques have been previously described for midline hernias associated with DRAM $[3,4,5]$. Some of the patients with DRAM have excess skin and, therefore, would need a dermolipectomy. Claus et al. described the subcutaneous onlay laparoscopic approach (SCOLA) for repairing ventral hernia and the plication of DRAM, particularly for the patients who do not need skin resection to avoid unaesthetic results of the midline incisions [6]. A similar REPA technique (preaponeurotic endoscopic repair) was described earlier by Muas, DMJ $[7,8]$. According to Claus et al., the SCOLA technique has some modifications concerning the REPA, such as the absence of relaxation incisions and the placement of a larger screen in a pre-aponeurotic position [6].

There were some differences from the previously described SCOLA technique in this particular case. The insufflation pressure was set to lower pressure as 6-8 $\mathrm{mmHg}$, which was adequate for a good view and to open the dissected space. We also selected the Ligasure device for initial dissection to get less smoke and clear vision, and excellent hemostasis. However, it takes more time than using a monopolar hook or scissors. It is evident that using a monopolar hook or scissor is faster but generates more smoke in the narrow space at the beginning of the procedure. In this particular case, the self-gripping polyester mesh was used, which was positioned easily and required less suture to additional fixation. A medium-weight polypropylene mesh can be used and fixed with sutures, glue, or tackers.

Seroma is the most frequent postoperative complication of the SCOLA procedure [6]. The early postoperative period was uneventful, and the patient was discharged on the second postoperative day. The drains were kept in place for eight days after surgery and removed after the drainage decreased to 
under $20 \mathrm{ml}$ per day. There were no complications, including seroma and surgical site infection in the first and third months of the postoperative period.

\section{Conclusion}

The SCOLA technique is a feasible and reproducible alternative for repairing midline hernias associated with DRAM for selected patients.

\section{Declarations}

\section{Conflict of Interest}

Dr. Halil Afsin Tasdelen has no conflicts of interest or financial ties to disclose.

\section{Ethical Approval}

Approval from an institutional board review is not required for a case report.

This article does not contain any studies with human participants or animals performed by the author.

\section{Informed Consent}

Informed consent was obtained from the patient for publication of this case report and the corresponding video.

\section{References}

1. Beer GM, Schuster A, Seifert B, Manestar M, Mihic-Probst D, Weber SA. The normal width of the linea alba in nulliparous women. Clin Anat. 2009 Sep;22(6):706-11. doi: 10.1002/ca.20836. PMID: 19637295.

2. Köhler G, Luketina RR, Emmanuel K. Sutured repair of primary small umbilical and epigastric hernias: concomitant rectus diastasis is a significant risk factor for recurrence. World J Surg. 2015 Jan;39(1):121-6; discussion 127.. doi: 10.1007/s00268-014-2765-y. PMID: 25217109.

3. Core GB, Mizgala CL, Bowen JC 3rd, Vasconez LO. Endoscopic abdominoplasty with repair of diastasis recti and abdominal wall hernia. Clin Plast Surg. 1995 Oct;22(4):707-22. PMID: 8846638.

4. Corrêa MA. Videoendoscopic subcutaneous techniques for aesthetic and reconstructive plastic surgery. Plast Reconstr Surg. 1995 Aug;96(2):446-53. doi: 10.1097/00006534-199508000-00030. PMID: 7624421.

5. Zukowski ML, Ash K, Spencer D, Malanoski M, Moore G. Endoscopic intracorporal abdominoplasty: a review of 85 cases. Plast Reconstr Surg. 1998 Aug;102(2):516-27. doi: 10.1097/00006534- 
199808000-00037. PMID: 9703093.

6. Claus CMP, Malcher F, Cavazzola LT, Furtado M, Morrell A, Azevedo M, Meirelles LG, Santos H, Garcia R. SUBCUTANEOUS ONLAY LAPAROSCOPIC APPROACH (SCOLA) FOR VENTRAL HERNIA AND RECTUS ABDOMINIS DIASTASIS REPAIR: TECHNICAL DESCRIPTION AND INITIAL RESULTS. Arq Bras Cir Dig. 2018 Dec 6;31(4):e1399. doi: 10.1590/0102-672020180001e1399. PMID: 30539974; PMCID: PMC6284377.

7. Muas DMJ, Verasay GF, Garcia WM. Reparación endoscó pica prefascial de la dia'stasis de los rectos: descripción de una nueva té cnica. Rev Hispanoam Hernia. 2017; 5(2):47-51.

8. Juárez Muas DM. Preaponeurotic endoscopic repair (REPA) of diastasis recti associated or not to midline hernias. Surg Endosc. 2019 Jun;33(6):1777-1782. doi: 10.1007/s00464-018-6450-3. Epub 2018 Sep 18. PMID: 30229321.

\section{Supplementary Files}

This is a list of supplementary files associated with this preprint. Click to download.

- SubcutaneousonlaylaparoscopicapproachSCOLA.mp4 